http://dx.doi.org/10.4314/bajopas.v12i1.22S

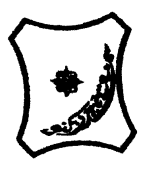

Bayero Journal of Pure and Applied Sciences, 12(1): 133 - 138

ISSN $2006-6996$

\title{
DISTRIBUTION AND SEXUAL DIMORPHISM OF PALM PRINT VARIABLE (PALM CREASES) AMONG HAUSA OF KANO AND ZARIA, NIGERIA
}

\author{
Usman Affan ${ }^{1}$ and El-Ladan I. S. ${ }^{1}$, \\ ${ }^{1}$ Department of Human Anatomy, Faculty of Medicine, Umaru Musa Yar'adua University, Katsina, \\ Nigeria
}

Corresponding author: usman.affan@umyu.edu.ng; GSM: +2348034409926

ABSTRACT

Dermatoglyphic features due to its permanency, genetic influence as well as number of easily observable and measurable characters may be considered one of the most suitable parameters for population variability and have been used extensively to characterize and differentiate human populations, hence, are highly suitable for studying population variation. The aim of the study is to analyze palm prints (palm creases) among Hausas of Kano and Zaria. A total of 600 subjects comprising of 300 participants from two original Hausa metropolis (Kano and Zaria) with 1:1 male to female ratio participated. Ink method was used to capture palm prints. Chi-square was used to determine the association between the variables. The frequency distribution of palmer creases showed that in the right hand only normal creases tend to occur higher in female (203 vs 172) the two metropolis combined. Similar pattern occurs, when the two metropolis were considered separately (Kano = 97 vs 75, Zaria = 106 vs 97). The same pattern of frequency distribution of palmer creases was observed in the left hand. A statistically significant gender differences $\left(X^{2}=-2.91, P=0.004\right.$ for right hand, and $X^{2}=-3.89, P<$ 0.001 for left hand) in the frequency distribution of type of palmer creases were noticed among the Hausa ethnic groups (both Kano and Zaria combined). However, when the two Hausa metropolis were separated, differences $\left(X^{2}=-2.71, P=0.007\right.$ for right hand, and $x^{2}=-4.66, P<0.001$ for left hand) were only noticed among the Hausas of Kano metropolis.

Key words: Palm prints, palm creases, Hausa, Kano, Zaria, Nigeria

\section{INTRODUCTION}

Dermatoglyphics, the study of dermal ridges on finger balls, palms and soles, with its qualitative and quantitative traits which are not adaptive and free from paratypic influences, provide a pertinent area of research to human population and geneticists interested in studying variation within and between populations (Reddy and Reddy, 2006; Muralidhar et al., 2011). Studies have shown that dermatoglyphics has found application in establishing ethnic differences, genetic inheritance and population studies respectively (Harich et al., 2002; Karmakar et al., 2006; Danborno and Garba, 2007).

Palm is the inner surface of the hand between the wrist and the fingers. Palm prints provide a vast source of identification information that can be used in a number of important fields, such as biometrics (Kong et al., 2009), dermatoglyphics (Qiao et al., 2005), and forensic science
(Ashbaugh, 1991). The general flow of skin, its pattern configuration, and minutiae formation, all contribute towards making the palm print a unique identification metric (Ashbaugh, 1999). However, many palm print identification systems are based on features, such as minutiae, ridge flow, singular points, and flexion creases which are formed during embryological development (Wu et al., 2004).

Previous studies reported that the pattern of palmar flexion creases among the Igbos of south eastern Nigeria, three major creases were reported, while about one-third had mid-palmar longitudinal crease (Okoro and Uloneme, 2004). The most common configuration of the palmar creases among Nigerians was line A (Radial longitudinal line), which showed $100 \%$ appearance among the three ethnic groups, for both right and left hands of male and female sexes. 
Special Conference Edition, November, 2019

Line B (Proximal transverse line) shows $100 \%$ presence for both right and left hands among Yoruba and Hausa ethnic groups, while it is present at $96.6 \%$ and $98.9 \%$ for both right and left hands for Igbo. Line C (distal transverse line) frequency is $99.5 \%$ for right and left hand of Yoruba ethnic group, present $100 \%$ on right hand and $31.6 \%$ of Igbo left hand. It is present at $96.6 \%$ and $98.9 \%$ of right and left hand respectively of Hausa ethnic group. Lines A and $B$ with radial base points occur in $53.2 \%$ of right hand and $50.7 \%$ of the left hand among the ethnic groups. Palmar prints with cascade of lines occurred in $31.3 \%$ of right hand and 33.6 $\%$ of left hand of the ethnic groups (Adetona, et al., 2012).

Of the palmar flexion creases, the transverse creases have received the most attention clinically especially when distal and proximal transverse lines fused to form a single transverse line from ulnar to radial border of the palm, called simian or 4-finger crease (Alter, 1970). Sydney line had also been described as the proximal transverse crease extending across the entire palm, while the distal crease appears normal. Purvis-Smith (Purvis-Smith and Menser, 1968) has called this a Sydney line as he observed it in patients examined in Sydney, Australia. The presence of simian crease; $0.5 \%$ and $0.2 \%$ right and left hand respectively among the three ethnic groups gives a precaution in diagnosing the simian line as abnormal within the Nigeria population. The recognition of the variants as outlined in different prints either as extra line on thenar eminence, numerous crease-crossing lines (cascade of lines), double lines $A$ and $B$, lines with bifurcations, lines with enclosure and variations in point of joining at lateral edges are important identification points (Adetona et al., 2012).

\section{MATERIALS AND METHODS}

Data for this study was collected from participants after informed verbal consent was obtained from those who are willing to participate in the survey. 600 subjects were selected using systematic random sampling method.

\section{Study Area}

The study was conducted in the two Hausa states which comprises of Kano and Zaria, which is the north west of Nigeria.

\section{Study Population}

The Hausa people are a powerful cultural and political group in Nigeria. One tradition holds that Abuyazid, sometimes also called Bayajida who was said to have fled from Baghdad following a quarrel with his father (Omolewa, 1986), founded Hausa land. Beginning from the eleventh century, seven independent Hausa towns were founded in Northern Nigeria namely, Biram, Daura, Gobir, Kano, Katsina, Zaria and Rano. These seven towns developed as strong trading Centre's, with economies based on intensive farming, cattle rearing, craft making and later slave trading. Kano and Katsina competed for the lucrative trans-Saharan trade with Kanem Borno, and for a time had to pay tribute to it.

The Kano Chronicle relates that the first king of Kano was Bagauda (999-1063) and that the city walls for which Kano is so famous were started in the reign of Bagauda's son, Gayamusa. The walls took a very long time to build and they were not completed until the reign of the fifth king of Kano, Yusa 1136-94. As at 1000 AD, Kano had already developed into a strong and prosperous trading centre, as a result of the trans-Saharan trade. By the 15th century Kano, Zaria, Katsina and Sokoto had grown into great centres of commerce (Crowther, 1962).

Various forms of taxes were developed through this period of rapid economic developments. These included the gandu, an agricultural tax levied on one - eighth of every farmer's crop which was introduced during the reign of Naguji who succeeded Yusa as the sixth king of Kano (Omolewa 1986). The zakkat, a type of taxation prescribed by the Holy Koran and levied on Moslems for charitable, religious and educational purposes; the kudin-kasa or land tax and the Jangali or cattle tax. In addition there was a plantation tax called shukka-shukka and kudin sarauta, an accession duty paid by every chief or holder of an office upon appointment. Finally, there was gado, a death duty on a deceased's estate paid to the Emir when there was no recognized or proven heir. 


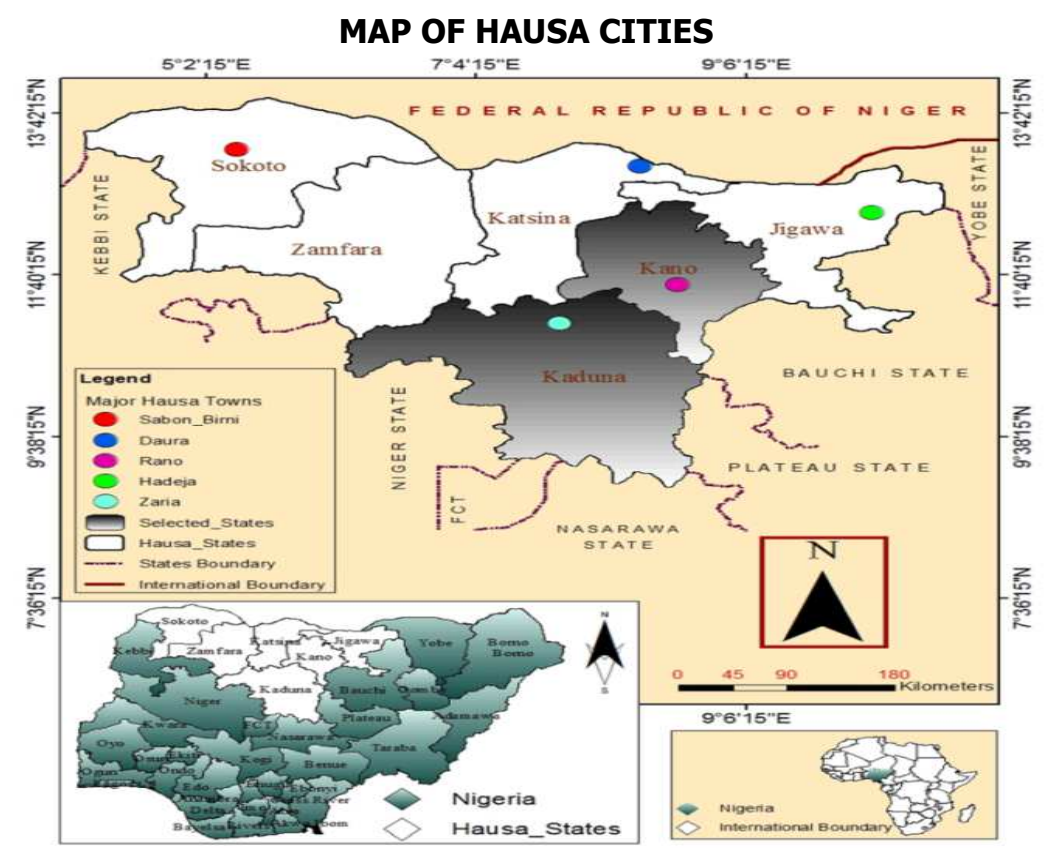

Fig. 1: Map of Hausa states showing the two study area (above): Map of Nigeria showing the Hausa states (below). Source: Geographic and information systems (GIS)

\section{Anthropometry}

Palm print: In this research work an offline method of palm print acquisition was employed, in which the palm print data was collected or captured from a non-digital source. Instead, the reference palm print was collected by printing with an ink on to a white paper sheet (Champed et al., 2004). The subjects were asked to sit in a relax position, wash and dry their hands. A small quantity of ink have been applied over the palm of the subject by simply pressing their palm on the provided stamp pad, the cupped region of the palm was smeared thoroughly and uniformly. A sheet of paper was keep at the edge of the table. The palm was imprint on the sheet of paper, taking care that the cupped regions of the palm are printed properly by pressing the dorsum of the palm of the subject. Care was taken to avoid any wrinkles and air bubbles. Then the palm prints was studied carefully using magnifying glass in bright light and the palm creases type parameters were obtained from the palm print.

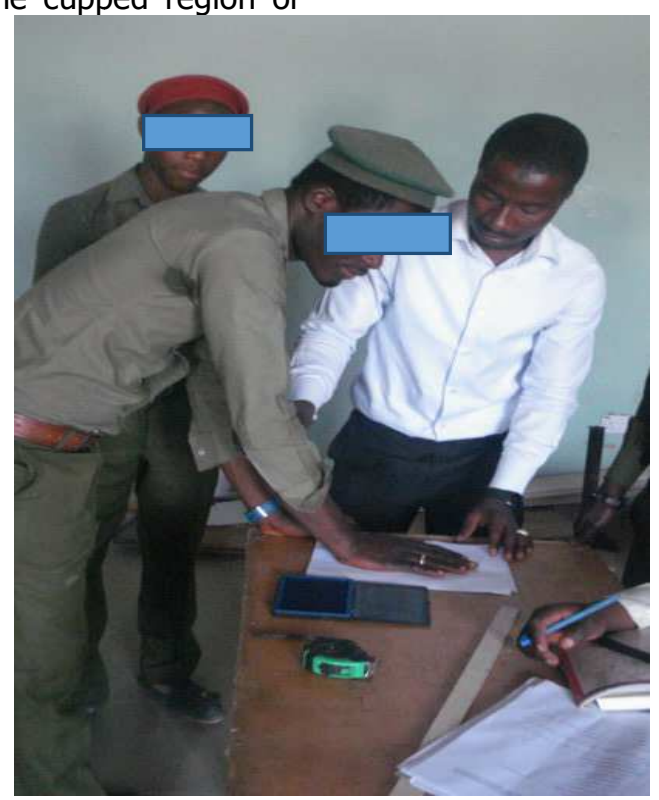

Plate I: Collection of the palm prints on the participant questionnaire 


\section{Statistical Analyses}

Data was reported using descriptive statistic of frequency/ percentages. A Chi-square test was used to test for association between qualitative variables. $\quad p<0.05$ was deemed statistically significant and SPSS version 22 (IBM, Corp., New York) was used for the data analysis.

\section{RESULTS}

The frequency distribution of palmer creases showed that in the right hand only normal creases tend to occur higher in female (203 vs 172) the two states combined. Similar pattern occur, when the two state were considered separately (Kano $=97$ vs 75, Zaria $=106$ vs 97) (Figure 1). The same pattern of frequency distribution of palmer creases was observed in the left hand (Figure 2). Significant gender differences $\left(\mathrm{X}^{2}=-2.91, \mathrm{P}=0.004\right.$ for right hand, and $x^{2}=-3.89, P<0.001$ for left hand) in the frequency distribution of type of palmer creases were noticed among the Hausa ethnic groups (both Kano and Zaria combined). However, when the two Hausa state were separated, differences $\left(X^{2}=-2.71, P=0.007\right.$ for right hand, and $X^{2}=-4.66, P<0.001$ for left hand) were only noticed among the Hausas of Kano State (Figures 1 and 2).

Table 1: Frequency distribution of palmer creases from Hausas of Kano and Zaria State (male $\mathrm{n}=$ 150 , female $n=150$ ).

\begin{tabular}{|c|c|c|c|c|c|c|c|}
\hline \multirow[b]{2}{*}{ States } & \multirow[b]{2}{*}{ Creases } & \multicolumn{2}{|c|}{ Right hand } & \multirow[b]{2}{*}{ Total (\%) } & \multicolumn{2}{|l|}{ Left hand } & \multirow[b]{2}{*}{ Total (\%) } \\
\hline & & Male (\%) & $\begin{array}{l}\text { Female } \\
(\%)\end{array}$ & & Male (\%) & $\begin{array}{l}\text { Female } \\
(\%)\end{array}$ & \\
\hline \multirow[t]{3}{*}{ Kano } & Normal & $75(50.0)$ & $97(64.7)^{*}$ & $\begin{array}{l}172 \\
(114.7)\end{array}$ & $68(45.3)$ & $\begin{array}{l}106 \\
(70.7)^{*}\end{array}$ & $174(116)$ \\
\hline & Simian & $57(38.0)$ & $44(29.3) *$ & $101(67.3)$ & $63(42.0)$ & $39(26.0)^{*}$ & $102(68.0)$ \\
\hline & Sydney & $18(12)$ & $9(6.0)^{*}$ & $27(18.0)$ & 19 (12.7) & $5(3.3)^{*}$ & $24(16.0)$ \\
\hline \multirow[t]{2}{*}{ Zaria } & Normal & $97(64.7)$ & $106(71.1)$ & $\begin{array}{l}203 \\
(135.8)\end{array}$ & $99(66.0)$ & $105(70.5)$ & $204(136.5)$ \\
\hline & $\begin{array}{l}\text { Simian } \\
\text { Sydney }\end{array}$ & $\begin{array}{l}47(31.3) \\
6(4.0)\end{array}$ & $\begin{array}{l}41(27.5) \\
2(1.3)\end{array}$ & $\begin{array}{l}88(58.8) \\
8(5.3)\end{array}$ & $\begin{array}{l}46(30.7) \\
5(3.3)\end{array}$ & $\begin{array}{l}37(24.8) \\
7(4.7)\end{array}$ & $\begin{array}{l}83(55.5) \\
12(8.0)\end{array}$ \\
\hline
\end{tabular}

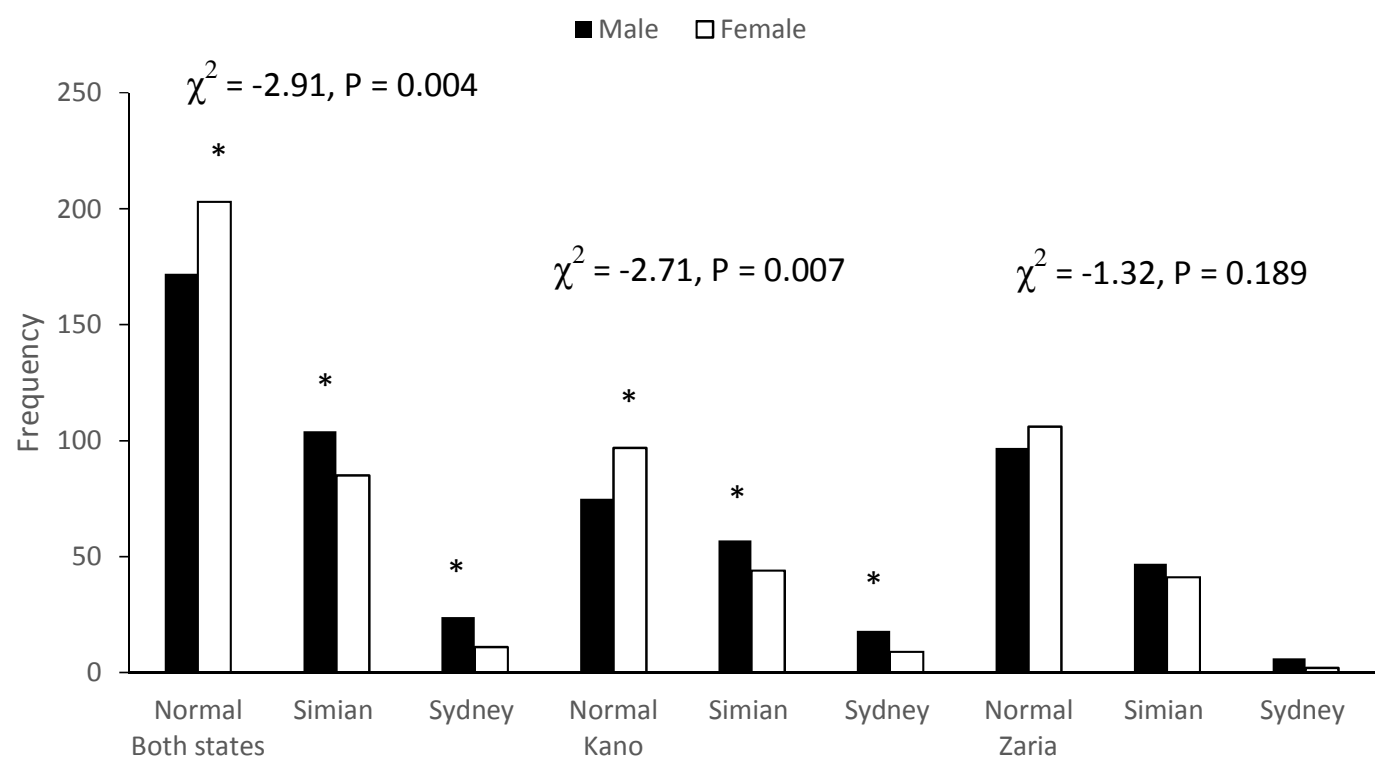

Fig. 1: Sexual dimorphism in frequency distribution of right palmer creases from Hausas of Kano and Zaria * $p<0.05$ 


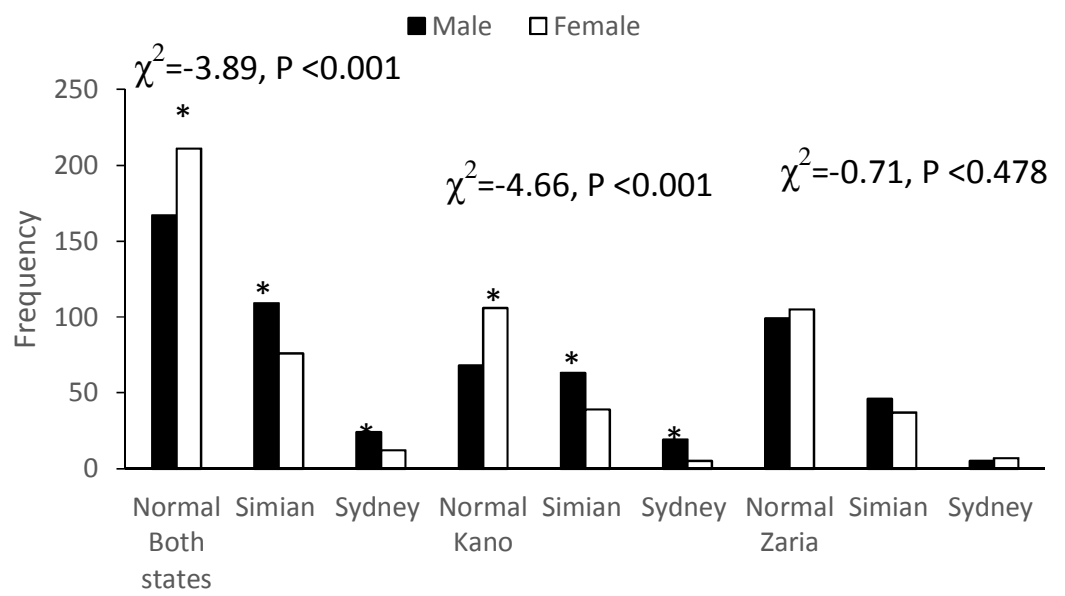

Fig. 2: Sexual dimorphism in frequency distribution of left palmer creases from Hausas of Kano and Zaria * $\mathrm{p}<0.05$

\section{DISCUSSION}

The frequency distribution of palmer creases showed that in the right hand only normal creases tend to occurred higher in female in the two state combined. Similar pattern occur, when the two state were considered separately. This same pattern of frequency distribution of palmer creases was observed in both right and left hand. Significant gender differences in the frequency distribution of type of palmer creases were notice among the Hausa ethnic groups. However, when the two Hausa state were separated, differences were only noticed among the Hausas of Kano State.

This is similar with what was reported by other authors as follows. In the study of pattern of palmar flexion creases among the Igbos of south eastern Nigeria, three major creases were reported, while about one-third had mid-palmar longitudinal crease (Okoro and Uloneme, 2004). The most common configuration of the palmar creases among Nigerians was line A (Radial longitudinal line), which showed $100 \%$ appearance among the three ethnic groups, for both right and left hands of male and female sexes. Line B (Proximal transverse line) shows $100 \%$ presence for both right and left hands among Yoruba and Hausa ethnic groups, while it is present at $96.6 \%$ and $98.9 \%$ for both right and left hands for Igbo. Line C (proximal transverse line) frequency is $99.5 \%$ for right and left hand of Yoruba ethnic group, present $100 \%$ on right hand and $31.6 \%$ of Igbo left hand. It is present at $96.6 \%$ and $98.9 \%$ of right and left hand respectively of Hausa ethnic group. Lines $A$ and $B$ with radial base points occur in $53.2 \%$ of right hand and $50.7 \%$ of the left hand among the ethnic groups. Palmar prints with cascade of lines occurred in $31.3 \%$ of right hand and $33.6 \%$ of left hand of the ethnic groups. The presence of simian crease; $0.5 \%$ and $0.2 \%$ right and left hand respectively among the three ethnic groups gives a precaution in diagnosing the simian line as abnormal within the Nigeria population (Adetona et al., 2012).

From this research it was noted that even though the normal creases have higher occurrence in all the three ethnic group in the study, but there is variation in term of the frequency among the three ethnic groups. This is in agreement with the present findings between the Hausas of the two Hausas state. The significant difference observed in the general Hausa population was seen to be contributed by the Hausas of the Kano state. This may clearly highlight the existence of features that may discriminate the Hausas based on their state of origins. It may also assumed that there may be intraethnic genetic variation among Hausa ethnic group as supported by the finding of the present study based on the qualitative dermatoglyphic variable.

\section{CONCLUSSION}

Significant gender differences in the frequency distribution of type of palmer creases were noticed among the Hausa ethnic groups. However, when the two Hausa state were separated, differences were only noticed among the Hausas of Kano State. This may clearly highlight the existence of features that may discriminate the Hausas based on their state of origins. It may also be assumed that there may be intraethnic genetic variation among Hausa ethnic group as supported by the finding of the present study based on the qualitative dermatoglyphic variable. 


\section{REFERENCES}

Adetona, M. O., Oladapo, O. O. and Akinyemi, J. O. (2012). Palmar flexion creases variants among Nigerians. African Journal of Biomedical Research, 15, 93-96.

Alter, M. (1970). Variation in palmer creases. American Journal of Disease in Childhood, 120, 424-431.

Ashbaugh, D.R. (1991). Palmar flexion crease identification. Journal of Forensic Identification, 41, 255-273.

Ashbaugh, D.R. (1999). Quantitative-Qualitative Friction Ridge Skin Analysis. Florida: CRC Press.

Champed, C., Lennard, C., Margot, P. and Stoilovic, M. (2004). Fingerprints and other Ridge Skin Impressions. Boca Raton, Florida: CRC Press.

Crowther, M. (1962). The story of Nigeria (London: Faber \& Faber).

Danborno, B. and Idris, G. (2007). Digital dermatoglyphics of Hausa ethnic group of Nigeria. Journal of Experimental and Clinical Anatomy. 6: 36-40.

Harrich, N., Esteban, E., Chafik, A. and Moral, P. (2002). Dermatologic characterization of barbars from Morocco. Qualitative and quantitative digital and palmer data. American Human Biology, 29: $442-456$.

Karmakar, B., Yakovenko, K. and Kobyliansky, E. (2006). Mode of inheritance of dermatoglyphics pattern intensity index on finger in five Indian population: A comparative study between individual traid and its factor. American journal of human biology, 18: 377-386.

Kong, A., Zhang, D. and Kamel, M. (2009). A survey of palmprint recognition. Pattern recognition, 42: 1408-1418.

Muralidhar, R. S., Ramesh, B. A. and Krupadanam, K. (2011). Finger Print Pattern in Different Blood Group, Journal of Indian Academic Medicine, 33: 4.

Okoro, I. O. and Uloneme, G. C. J. (2004). The pattern of palmar flexion creases among the Igbos of south eastern Nigeria. Journal of Experimental and Clinical Anatomy 3 (2), 38-40.

Omolewa, M. (1986). Certificate history of Nigeria (Lagos, Longman Group), p viii and 264.

Purvis-Smith, S. G. and Menser, M. A. (1968). Dermatoglyphics in adults with congenital Rubella. Lancet, 2: 141-3.

Qiao, Y., Li, Z., Wang, Q., Zeng, Y. and Liang, K. (2005). Identification of palm print using dermatoglyphics analysis and detection system. Medical Engineering and Physics, 27: 229-235.

Reddy, B.K.C. and Reddy, K.S.N. (2006). A study of salmar dermatoglyphics among Sugalis, a tribal population of Andhra pradesh. Anthropologist, 8: 21-24.

Wu, X., Zhang, D. and Wang, B. (2004). Palm print classification using principal lines. Pattern Recognition, 37: 1987-1988. 